\title{
Research on Big Data Curriculum System and Specialty Construct at Home and Abroad
}

\author{
Xiaofang Zhang, Fen Wang, Xiaotao Huang \\ Network and Compute Center, Huazhong University of Science and Technology, Wuhan, China (whuci@163.com)
}

\begin{abstract}
Along with the growing popularity and widely using in critical business for all works of life and profession of big data technology, there is a growing perception in education field at home and abroad that setting big data correlated curriculum and specialty in colleges and universities. According to relative emphasis of talent training, big data education is mainly divided into three directions in foreign countries: big data analysis for Business College, big data platform for Computer College, and deep compute analysis for Science College. In China, big data courses are offered for undergraduates in more and more universities. Graduate specialty in big data technology \& application is also set up in Beihang University and Xidian University.
\end{abstract}

Keywords-Big Data, Curriculum System, Specialty Construct

\section{国内外大数据课程体系与专业建设调查研究}

\author{
张晓芳 王芬 黄晓涛 \\ 华中科技大学网络与计算中心, 武汉, 湖北, 中国
}

摘 要 随着大数据技术的日益普及和在各行各业关键业务中的广泛应用, 在高校中设置大数据相关课程和专业 (专业方向) 已成为国内外教育界的紧迫任务和共识。目前, 国外已有多所知名高校开展大数据这一方向的课程体系与专业建设, 如 DePaul, Boston University, NCSU 等。根据知识范围与人才培养的侧重点不同, 主要分为三个方向: 面向商学院、管理学院、财经学院的大数据分 析方向、面向计算机学院与软件学院的大数据平台方向、面向理学院的深度计算分析方向。国内目前也有多所高校在本科生中开设 了大数据的相关课程, 并有大学设置了大数据技术与应用研究生专业。

关键词 大数据, 课程体系, 专业建设

\section{1. 引言}

随着互联网的飞速发展, 企业计算、云计算、物联网 等各种应用的涌现, “大数据”应运而生。如何使用计算机 技术和软件技术, 可靠地管理和存储海量数据并高效地处 理和分析海量数据, 实现云计算、企业计算等新的应用, 成为 IT 界所关注的问题 ${ }^{[1]}$ 。

“大数据” (Big Data) 指一般的软件工具难以捕捉、管 理和分析的大容量数据。“大数据”之“大”, 并不仅仅在于 “容量之大”，更大的意义在于：通过对海量数据的交换、 整合和分析, 发现新的知识, 创造新的价值, 带来“大知识”、 “大科技”、“大利润”和“大发展”。

云计算、企业计算、大数据等作为 21 世纪的新兴 IT 应用, 反映着时代最前沿的 IT 技术和知识。大数据及相关

2013 华中科技大学教学研究项目支持 (资助号：13039)
知识代表着当前的 IT 时代潮流和未来趋势, 大数据系列课 程的开设和大数据专业方向的设置是时代发展的需要。目 前, 国内外的很多高校都陆续开始在计算机、管理、金融 等专业中开设大数据的系列课程, 设置以大数据为核心的 人才培养方案和课程体系。

\section{2. 国外大数据课程体系与专业建设}

目前, 国外已有多所知名高校开展大数据这一方向的 课程体系与专业建设, 如 DePaul, Boston University, NCSU 等。根据知识范围与人才培养的侧重点不同, 主要分为三 个方向: 面向商学院、管理学院、财经学院的大数据分析 方向、面向计算机学院与软件学院的大数据平台方向、面 向理学院的深度计算分析方向。表 1 为国外大数据课程体 系参考。 
表 1 国外大数据课程体系

\begin{tabular}{|c|c|c|}
\hline $\begin{array}{c}\text { 大数据分析方向 } \\
\text { (商学院、管理学院) }\end{array}$ & $\begin{array}{c}\text { 大数据平台方向 } \\
\text { (计算机学院、软件学院) }\end{array}$ & $\begin{array}{c}\text { 深度计算分析方向 } \\
\text { (理学院) }\end{array}$ \\
\hline $\begin{array}{l}\text { Knowledge Discovery } \\
\text { Decision in Market Mgmt } \\
\text { Customer Relationship Mgmt } \\
\text { Analytic Tools for Business } \\
\text { Data Mining \& Analysis } \\
\text { Business Intelligence } \\
\text { Image Analysis \& Visualization } \\
\text { Precision Marketing } \\
\text { Predictive Analytics } \\
\text { Internet and Interactive Mktg } \\
\text { Data Querying \& Reporting } \\
\text { Advanced Data Analytics } \\
\text { Inventory Management } \\
\text { Supply Chain Optimization } \\
\text { Channel Performance } \\
\text { Policy, Security, Privacy }\end{array}$ & $\begin{array}{l}\text { Information Structures } \\
\text { Quantitative Methods } \\
\text { Database Design } \\
\text { Information Systems Analysis \& } \\
\text { Design } \\
\text { IT Strategy \& Management } \\
\text { Data governance \& Security } \\
\text { IT Security Policies and Procedures } \\
\text { Dating Mining for BI } \\
\text { Design \& Implement Data Warehouse } \\
\text { Analysis \& Information Mgmt } \\
\text { Enterprise Architecture Enterprise } \\
\text { Information Design } \\
\text { Analytics and Info Mgmt Database } \\
\text { Administration }\end{array}$ & $\begin{array}{l}\text { Analytics Tools \& Techniques } \\
\text { Data Querying \& Reporting } \\
\text { Data Cleaning } \\
\text { Statistical Programming } \\
\text { Data Mining } \\
\text { Geospatial Data Analytics } \\
\text { Data Visualization } \\
\text { Multiple Linear Regression } \\
\text { Logistics Regression } \\
\text { Forecasting } \\
\text { Linear Programming } \\
\text { Advanced Modeling } \\
\text { Statistical Methods for Process } \\
\text { Improvement } \\
\text { Data Privacy \& Security Advanced } \\
\text { Data \& Text Mining } \\
\text { Financial Analytics } \\
\text { Risk Analytics }\end{array}$ \\
\hline
\end{tabular}

\section{3. 国内大数据学科建设与人才培养}

\section{1 北航大数据技术与应用研究生专业}

2013 年 1 月, 北京航空航天大学联合慧科教育成立国 内首个“大数据技术与应用”软件工程硕士项目, 旨在培养 数据领域的科学家和工程师。北航大数据硕士项目旨在培 养数据领域的科学家和工程师, 除了进行软件工程的传统 教育外, 将在教学过程中引入更多实战场景, 让学生在解 决实践问题中学习大数据相关理论。
北京航空航天大学大数据专业从大数据应用的三个主 要层面（数据管理、系统开发、海量数据分析与挖掘）系 统地帮助企业掌握大数据应用中的各种典型问题的解决办 法, 包括实现和分析协同过滤算法、运行和学习分类算法、 分布式 Hadoop 集群的搭建和基准测试、分布式 Hbase 集群 的搭建和基准测试、实现一个基于 MapReduce 的并行算法、 部署 Hive 并实现数据操作等, 实际提升企业解决实际问题 的能力。其专业课程体系如表 2 所示。

表 2 北京航空航天大学大数据技术与应用研究生专业课程体系

\begin{tabular}{|l|l|l|l|}
\hline \multicolumn{1}{|c|}{ 公共基础课程 } & \multicolumn{1}{|c|}{ 专业基础课程 } & \multicolumn{1}{|c|}{ 专业核心课程 (1) } & \multicolumn{1}{|}{ 专业核心课程 (2) } \\
\hline 概率论与数理统计 & 算法分析与统计 & 分布式系统 & 商务智能 \\
科技协作与沟通技巧 & 程序设计及编程语言原理 & 流数据分析技术 & 计算广告学 \\
英语 & 计算机网络 (复杂网络) & 数据挖掘与数据仓库 & 统计分析技术 \\
自然辩证法 & 数据库概论 & 高级数据库系统 & 搜索引擎系统应用 \\
& & 多元统计分析与 R 语言建模 & 社交网络分析 \\
& & 云计算技术原理 & 机器学习与模式识别 \\
& & 一级工程实践 (DB 系统) & 数据可视化技术 \\
& & & 前沿技术讲座 \\
& & & 二级工程实践 \\
& & & (Hadoop、MapReduce) \\
\hline
\end{tabular}




\section{2 西安电子科技大学软件学院大数据技术与应用专业}

2014 年, 西安电子科技大学设立大数据技术与应用专 业, 联合国家工信部 CSIP 移动云计算教育培训中心、工信 部-百度互联网营销学院 (慧科教育) 开设大数据技术与应 用专业硕士方向, 培养大数据领域的应用型、复合型、国 际化的高级人才。

大数据专业从大数据应用的三个主要层面 (即大数据 平台架构及搭建、应用开发、海量数据分析及可视化), 整 理并分析其中的核心技术, 同时梳理大数据应用中的各种
典型问题, 包括海量数据分布式处理系统的设计和搭建、 分布式文件存储和分布式数据处理能力、大规模数据存储、 实时计算系统的规划设计、实现一个基于 MapReduce 的并 行算法、部署 Hive 并实现一个数据库的操作等, 设计基于 科研和实践应用两方面并重的课程体系, 使学生具备大数 据平台架构和高级分析能力, 辅以线上课程的辅助和支撑, 强化学生综合能力, 以及解决企业实际问题的能力。其专 业课程体系如表 3 所示。

表 3 西安电子科技大学软件学院研究生大数据技术与应用专业课程体系

\begin{tabular}{|c|c|c|c|c|}
\hline $\begin{array}{c}\text { 第一阶段 } \\
\text { (企业级开发技术实训) }\end{array}$ & $\begin{array}{c}\text { 第二阶段 } \\
\text { (移动端开发技术) }\end{array}$ & $\begin{array}{l}\text { 第三阶段 } \\
\text { (硕士课) }\end{array}$ & $\begin{array}{c}\text { 第四阶段 } \\
\text { (硕士课+个人能力提升) } \\
\end{array}$ & 第五阶段 \\
\hline $\begin{array}{l}\text { Web UI 设计 } \\
\text { 企业门户设计实践 } \\
\text { 云计算概述 } \\
\text { 数据库开发设计 } \\
\text { 初识亚马逊一AWS 实战 } \\
\text { JAVA 核心技术 } \\
\text { JAVA Web 开发技术 } \\
\text { 企业核心业务系统设计实践 } \\
\text { 开源云框架设计 } \\
\text { 企业级框架应用开发技术 } \\
\text { 企业商用项目的设计、开发与实施 } \\
\text { 大数据细化与应用 }\end{array}$ & $\begin{array}{l}\text { 企业前沿框架技术 } \\
\text { Android 平台移动计算开发 } \\
\text { Android 平台系统实战 } \\
\text { 移动云计算企业实战 } \\
\text { 大数据处理技术 } \\
\text { (Hadoop) }\end{array}$ & $\begin{array}{l}\text { 计算机系统基础 } \\
\text { 工程数学 } \\
\text { 数据库概论 } \\
\text { 机器学习与模式识别 } \\
\text { 搜索引擎系统应用 } \\
\text { 数据仓库与数据挖掘 }\end{array}$ & $\begin{array}{l}\text { 社交网络分析 } \\
\text { 流数据分析技术 } \\
\text { 多元统计分析与 R 语言建模 } \\
\text { 数据可视化技术 } \\
\text { 商业智能 } \\
\text { 计算广告学 } \\
\text { 大数据技术与应用前沿技术讲座 } \\
\text { 职业生涯规划 }\end{array}$ & $\begin{array}{c}\text { 企业实习 } \\
\text { 及论文答 } \\
\text { 辩 }\end{array}$ \\
\hline
\end{tabular}

\section{IBM 大数据大学合作项目}

IBM 的大数据战略以 “智慧的分析洞察 (Smarter Analytics)”为核心, 整合了“大数据平台”和“大数据分析”两 大实力，目前已构建完成业界最完整的大数据价值体系。

“大数据平台”架构包括 Hadoop 系统、流计算、数据仓 库和信息整合与治理四大核心技术能力, 突破了传统数据 仓库和数据管理理念, 能够为企业组织提供实时分析信息 流和因特网范围信息源的能力, 实现更为经济高效的大数 据管理和整合治理, 并为在此之上的大数据分析奠定坚实 的基础。

绩效管理、风险分析、决策管理和内容分析等构成完 整的“大数据分析”能力, 为决策制定者 提供全面、统一且 准确的信息, 帮助他们在激增的数据中获取洞察, 发掘商 业机遇和价值, 制定更为有效的决策最终提高业绩。其卓 越的大数据能力集中体现在一系列领先分析技术和工具 上：包括全球领先的商业智能和绩效管理软件 Cognos、预 测分析软件 SPSS、风险管理软件 OpenPages、企业风险分
析软件 Algorithmics 以及薪酬和销售绩效管理软件 Varicent 等。

IBM 对大数据价值体系的梳理和构建, 为高校进行大 数据人才培养及学科建设, 提供了一个有益的参考。 2013 年, IBM 全面启动与高校在大数据领域的合作, 充分利用 在技术方面的雄厚实力、研发团队解决具有空前规模和复 杂性问题的能力, 以及成熟的高校合作模式与项目的优势, 从协作创新、学科建设与人才培养、校园活动及国际合作 这四大方向开展与高校的大数据合作, 推动 “大数据平台” 和“大数据分析”的产学研合作及高价值人才培养。

大数据分析专业 (专业方向) 共建案例: 2012 年, IBM 与西安交通大学软件学院共建针对研究生的业务分 析系。首届业务分析系学生将在 2015 年 6 月毕业, 计划与 亟需大数据分析人才的企业合作在 2014 年举办校园招聘 会, 建立端到端的应用型人才培养渠道。其专业课程体系 如表 4 所示。 
表 4 西安交通大学软件学院业务分析系课程体系

\begin{tabular}{|c|c|c|c|}
\hline 前导课程 & 核心技术 & 工具协作 & 行业高级课程 \\
\hline 数理统计 & 数据准备 & SPSS & 保险理赔决策分析系统 \\
概率分析 & 回归分析 & Cognos & 客户管理决策分析系统 \\
数据库系统概论 & 时序分析 & DB2 & \\
人工智能导论 & 聚类分析 & & \\
& 关联分析 & & \\
& 预测分析 & & \\
& & & \\
\end{tabular}

大数据平台专业 (专业方向) 共建案例: 2011 年, IBM 启动与北京交通大学软件学院就研究生信息管理专业共建 的计划。该计划旨在与高校一起共同培训高端的信息管理 人才, 将业界最新的信息管理技术与软件产品, 以及实践 教学引入高等教育中去, 以培养符合信息管理业界需求的 软件人才。IBM 与北京交通大学软件学院共建 5 门信息 管理方向的核心课程, 共同开发课件, 首轮授课由 IBM 资 深工程师担任讲师, 后续由软件学院教师负责教学。2012 年 9 月开课, 2013 年 6 月完成所有课程的首次授课。2014 年将通过与业务伙伴合作开始新一轮的课程教学。

\section{5. 结论}

调研了国内外相关专业大数据课程体系和专业设置情
况。国外主要包括面向商学院、管理学院、财经学院的大 数据分析方向、面向计算机学院与软件学院的大数据平台 方向、面向理学院的深度计算分析方向的课程设置情况; 国内重点考察了北京航空航天大学大数据技术与应用研究 生专业和西安电子科技大学软件学院大数据技术与应用专 业的课程设置情况。通过调查发现, 国外大学更侧重于大 数据理论的研究, 而国内大学更注重于大数据的实现技术。

\section{参考文献(References)}

[1] X. Meng and X. Ci, "Big Data Management: Concepts, Techniques and Challenges", Chinese Journal of Computer Research and Development, vol. 50, no. 1, pp. 146-169, 2013. 